\title{
Self-regulation and expatriate adjustment: the role of regulatory fit
}

Article

Accepted Version

Creative Commons: Attribution-Noncommercial-No Derivative Works 4.0

Kumar, R., Budhwar, P., Patel, C. and Varma, A. (2019) Selfregulation and expatriate adjustment: the role of regulatory fit. Human Resource Management Review, 29 (4). 100666. ISSN 1053-4822 doi: https://doi.org/10.1016/j.hrmr.2018.09.002 Available at https://centaur.reading.ac.uk/79817/

It is advisable to refer to the publisher's version if you intend to cite from the work. See Guidance on citing.

To link to this article DOI: http://dx.doi.org/10.1016/j.hrmr.2018.09.002

Publisher: Elsevier

All outputs in CentAUR are protected by Intellectual Property Rights law, including copyright law. Copyright and IPR is retained by the creators or other copyright holders. Terms and conditions for use of this material are defined in the End User Agreement.

\section{www.reading.ac.uk/centaur}

\section{CentAUR}

Central Archive at the University of Reading

Reading's research outputs online 
Self-Regulation and Expatriate Adjustment: The Role of Regulatory Fit

\author{
Rajesh Kumar, PhD \\ International Strategic Consultants \\ E-mail: rjk499@yahoo.com \\ * Pawan Budhwar, PhD \\ Professor of International HRM, \\ Work and Organisational Psychology Group, \\ Aston Business School, U.K. \\ E-mail:p.s.budhwar@aston.ac.uk
}

Charmi Patel, PhD

Associate Professor in IHRM

International Business and Strategy Group

Henley Business School, U.K.

E-mail: charmi.patel@henley.ac.uk

$\&$

\author{
Arup Varma, $\mathrm{PhD}$ \\ Quinlan School of Business \\ Loyola University Chicago, USA \\ E-mail: Avarma@luc.edu
}

* Corresponding author 


\begin{abstract}
In this paper, we draw on the construct of regulatory fit in explaining how expatriates manage interactional and work-related discrepancies in diverse cultural contexts. When expatriates go overseas, they are often faced with a set of expectations that are at variance with their home country norms and these differences in expectations generate discrepancies. The emergence of discrepancies in an alien cultural context exacerbates the uncertainties facing the expatriate, though the response to uncertainty varies between expatriates. We posit that expatriates with a promotion-focused self-regulatory system are focused on maximizing gains leading them to manage uncertainty through experimentation whereas expatriates with a prevention-focused self-regulatory system are oriented to minimizing losses leading them to manage uncertainty by persisting with the status-quo. Utilizing insights from motivational science and by linking the self-regulatory processes to the cultural context, we develop a framework and propositions for expatriate adaptation in loose and tight cultures. We present managerial implications of our model and offer guidance for testing the framework.
\end{abstract}

Key Words: Expatriate management, Regulatory focus, Tight-loose culture 


\section{Introduction}

Expatriate assignments are critical to successful strategy implementation for multinational companies (MNCs), yet organizations continue to struggle with finding the right formula that would help ensure a successful stint for the expatriate (e.g., Takeuchi, Wang \& Marinova, 2005; Takeuchi, Shay, \& Li, 2008; Fang, Jiang, Makino, \& Beamish, 2010; van der Laken, van Engen, van Veldhoven, \& Paauwe, 2016). Expatriate adjustment is considered crucial both for the success of the organization and the individual and refers to the level of comfort that individual experiences in an alien culture, one that is different from one's own (Shaffer, Reiche, Dimitrova et al., 2016).

When an expatriate goes overseas, a discrepancy emerges between what an expatriate is used to and the host country environment, which imposes a new set of demands in relation to work, interacting with host country nationals $(\mathrm{HCNs})$, and in relation to general adjustment (Black \& Mendenhall, 1991). A discrepancy represents a deviation between the norms of the home country of the expatriate and the norms of the host country to which the expatriate has been assigned. The emergence of discrepancies increases the uncertainty for expatriates with uncertainty reduction being a critical aspect of expatriate adjustment (Shaffer, Harrison \& Giley, 1999; Stock \& Genisyurek, 2012; Takeuchi, 2010). The greater the cultural distance, the greater the uncertainty that the expatriates are confronted with (see also, Wang \& Varma, 2017).

So, what determines the ability of expatriates to manage uncertainty? At the individual level, scholars have highlighted the importance of an expatriates' motivation in coping with uncertainty that is entailed in expatriate adjustment (Wang \& Takeuchi, 2007). Here, Firth, Chen, Kirkman and Kim (2014) suggest that expatriates who have a high level of cross cultural motivation are more likely to be proactive and will put in the extra effort. The construct of cross-cultural motivation as advanced by these authors comprises the notion of 
cultural self-efficacy and that of cultural intrinsic motivation. What is missing here though, is an emphasis on intrapersonal motivational processes that focus on issues pertaining to “... effort, goal setting, and goal striving, which are likely central to the adjustment process" (Firth et al., 2014: 296).

The objective of this paper is to develop a process model focusing on intrapersonal motivational processes explicating how expatriates deal with interactional and work-related discrepancies encountered in a novel cultural environment. Our starting premise is that selfregulation is critical to successful goal pursuit since it involves an individual monitoring his/her progress towards attaining a goal and taking steps to correct any unfavorable discrepancies that may have emerged between the individual's goals and the progress that he/she is making in accomplishing them (Lanaj, Chang, \& Johnson, 2012; Tsui \& Ashford, 1994).

In explaining these intrapersonal motivational processes, we draw upon the lens of Higgins (1997) regulatory focus theory (Johnson, Smith, Wallace, Hill, \& Baron, 2015). This theory has been used to explain goal attainment in domains such as negotiations (Appelt \& Higgins, 2010), alliance management (Das \& Kumar, 2011; Kumar \& Higgins, 2012), safety behavior (Wallace \& Chen, 2006), work-related behavior (Kark \& Van Dijk, 2007; Shin et al., 2017; Wallace et al., 2013) and lately for burnout in expatriates (Silbiger, Berger, Narnes, \& Renwick, 2017). A central tenet of the theory is that there are two alternative selfregulatory processes, namely a promotion and a prevention focus (Higgins, 1997). The promotion-focused self-regulatory system focuses on individuals realizing their ideals through growth and advancement whereas a prevention-focused self-regulatory system has, as its preeminent focus, security with the objective being to engage in vigilant behavior to avoid undesirable outcomes. More than 200 studies have been published utilizing this construct 
(Johnson et al., 2015) and the construct has also shown to be robust across cultures (Lee, 2000).

The proposed conceptual model enriches expatriate research on a number of dimensions. First, as Takeuchi (2010) notes, a major limitation of the extant literature is that (but for one exception see Van Viannen, Pater, Kristof-Brown \& Johnson, 2004) the field has not systematically investigated the dynamics of expatriate adjustment from the standpoint of an interaction between individual characteristics and situational characteristics. A personsituation interaction perspective (Lee \& Antonakis, 2014) will be helpful in deepening our understanding of the dynamics of expatriate adjustment. This argument is based on the premise that individuals differ in terms of their cognition, abilities, and motivations suggesting that two different individuals may adapt in very different ways. As such, behavior is a function of both individual characteristics and situational constraints (Chatman, 1989; Nguyen, Johnson, Collins, \& Parket, 2017). Accordingly, we need to consider both in studying the dynamics of expatriate adjustment.

Another contribution is the emphasis that is given to exploring the nature of emotions that expatriates might experience in their intercultural encounters. Although stress has been considered in extant research on expatriate adjustment, there is very little work exploring the impact of discrete emotions on expatriate adjustment. Emotions are high intensity affective states that last for a short duration but nevertheless can be highly consequential in shaping interpersonal exchanges among individuals (Diefendorff \& Greguras, 2009; Lazarus, 1991; Stea, Pedersen, \& Foss, 2017). Positive emotions arise when an actor has been able to achieve his/her goals and negative emotions arise when s/he is thwarted from realizing their objectives. As an expatriate enters a novel cultural environment s/he is likely to be thwarted in achieving his/her goals setting the stage for the emergence of negative emotions such as anger or anxiety. Thus, it is important to explore how an expatriate copes with the emotions that 
$\mathrm{s} /$ he is experiencing and the implications this has for his/her work and/or interactional adjustment. This is an issue that has rarely been addressed by expatriate researchers even as the field of organization science is now more than ready to embrace the study of emotions (e.g., Ashkanasy, 2003; Barsade \& Gibson, 2007; Elfenbein, 2007). We believe this is a critical omission in the literature, as emotions impact behavior (Lawler \& Thyne, 1999), shape judgments (Jones \& George, 1999) and influence the reactions of the other party (Van Kleef, 2009).

The theory being advanced here also draws upon the distinction between values and norms. Values are internalized beliefs that are held by an individual whereas norms are social rules that govern an individual's behavior (Chua, Roth, \& Lemoine, 2015). National culture has been a central construct in the study of cross-cultural organizational behavior and has been predominantly studied through the lens of value differences (e.g., Erez \& Earley, 1987; Hofstede, 1991; Budhwar \& Sparrow, 2002). Some have objected to the notion of studying cultural differences solely on the basis of differences in values (Earley \& Mosakowski, 2002; Gelfand, Nishii, \& Raver, 2006; Morris et al., 2000). The role of situational constraints and/or the social structure within which individuals interact is underplayed and this may be limiting as behavior may be a function both of individual related variables (values) and the social norms (Gelfand et al., 2006). We seek to redress this deficiency by recognizing that expatriates are not only confronted with both, superficial and deep level cultural differences, but equally they must cope with the fact that in tight cultures, as opposed to loose cultures, the social norms are much stronger, and the consequences of violation are severe (Gelfand et al., 2006). More specifically, in tight cultures, little deviation is allowed from the existing norms and any infraction is punished severely, whereas loose cultures are more accepting and tolerant of deviations. The construct of tight-loose cultures thus provides a useful analytical 
tool for studying self-regulation in varying cultural contexts as it suggests that the origins and the consequences of discrepancies may be different across varying cultural contexts.

Our model focuses on how expatriates cope with interactional and work-related discrepancies as opposed to general adjustment discrepancies for the fundamental reason that the latter (e.g., climate, food, general ambience) are not directly linked to an expatriate's selfregulatory system and are thus not emphasized in this paper. In other words, both promotionfocused and prevention-focused expatriates would need to address issues of general adjustment discrepancies, but there self-regulatory focus would have minimal, if any, impact on the way they approach these issues.

We begin by outlining the key features of our model (see Figure 1). We then elaborate upon the tightness-looseness dimension which is a useful way of defining the social context within which expatriates have to function. This is then followed by a discussion of the promotion-focused and prevention-focused self-regulation strategies and a discussion of the idea of regulatory fit. Specific propositions are developed and illustrated through the use of illustrative examples. The propositions are also amenable to empirical testing and we propose methods suitable for such endeavors. In the conclusion section, we summarize the core theoretical contributions of the paper, discuss the managerial implications, and outline future research directions.

\section{Insert Figure 1 About Here}

\section{Regulatory fit and managing discrepancies}

Figure 1 highlights the key aspects of our framework. The presence of fit suggests that the strategies used by an expatriate to reduce discrepancies and hence uncertainties are consistent with their regulatory orientation - be it a promotion or a prevention focus (Higgins, 
2000). We posit that non-fit generates negative emotions, face threat, and induces identity related conflicts. A key implication of non-fit is that the ability of the expatriate to cope with discrepancies and hence uncertainty is likely to be much lower than might have been the case otherwise. As a non-fit emerges the expatriate attempts to employ repair strategies to lessen the discrepancies emerging from non-fit. Host country co-worker support will facilitate expatriate adjustment and the absence of such support will make adjustment that much more difficult. It has been widely recognized in the literature that host country co-worker support is critical in facilitating expatriate adaptation (e.g., Varma, Toh, \& Budhwar, 2006). The coworker can sensitize the expatriate to both the sins of commission and the sins of omission and insofar as that is the case considering their involvement becomes crucial to studying expatriate adjustment. Spousal support may also be critical in reducing work-family conflict and to that extent facilitating expatriate adjustment. The framework being advanced in this paper incorporates both motivational as well as structural variables in developing a theory of expatriate adjustment. Studies linking regulatory focus to expatriate adjustment have begun to appear in the literature, but these studies only examine the linkage between regulatory foci and expatriate adjustment and in the process neglect the role of regulatory fit (e.g., Lee, Hung, Chien, Zhang, \& Hsu, 2017).

\subsection{Cultural tightness and looseness}

The construct of tightness-looseness highlights the role of social norms in shaping behavior. This consists of two components, namely (a) the strength of social norms, and (b) tolerance of deviant behavior (Gelfand, Nishii, \& Raver, 2006; Gelfand, 2012; Gelfand et al., 2011). The fundamental distinction between tight and loose cultures is that in the former, norms are stated clearly and any deviation from expected behavior attracts penalty. Also, the tightness-looseness of a culture influences different facets of life in a given culture (Chan et 
al., 1996). It has been maintained that individual behavior will be more a function of normative pressures in tight cultures, whereas it will be more dependent on individual attitudes in a loose culture. Further, the sanctioning processes will be more developed in tight as opposed to loose cultures reflecting the fact that deviation from extant norms is less acceptable. Moreover, values such as conformity or stability may be more dominant in tight cultures whereas values such as risk taking may prevail in a loose culture.

Gelfand et al. (2006) point out that the construct of tightness-looseness is analytically distinct from the value dimensions of individualism-collectivism, power distance, and/or uncertainty avoidance (but for a different perspective see Minkov, Blagoev, \& Hofstede, 2012). As they note (2006: 1227), "Tightness-looseness is unique and complementary to other cultural dimensions". Here, it should be noted that prior research has shown that tightnesslooseness is only moderately correlated with collectivism (Triandis, 1989). Germany, Singapore, and Korea are examples of tight cultures whereas the United States and Australia are representative of loose cultures.

We argue that the construct of tightness-looseness is uniquely relevant to the study of expatriate adjustment for a multitude of reasons. First, the construct attests to the importance of the strength of the norms and sanctions that the expatriate may be confronted with as s/he crosses cultural boundaries. The lack of fit between the norms and sanctions in the expatriate's home culture and that in the host culture may give rise to numerous discrepancies in the arena of work and/or interaction with host country nationals. How the expatriate deals with these discrepancies critically shapes expatriate adaptation. The greater the distance between the expatriate's cultural background and that of the host culture the more problematical the discrepancies might be. Second, the construct predicts that there is likely to be a stronger linkage between cultural values and outcomes in tighter as opposed to looser societies. In tighter societies, individuals have less or no option but to follow the prescribed 
norms as social sanctioning for deviant behavior is severe. In other words, there is likely to be less flexibility in terms of how they can behave. In a meta-analytic review of Hofstede's cultural value dimensions that incorporated 598 studies, Taras, Kirkman and Steel (2010) found support for a stronger linkage between values and outcomes in tight as opposed to loose societies confirming the basic prediction of the theory. This would attest to the fact that this dimension provides additional explanatory power beyond what is provided by Hofstede's value dimensions. When an expatriate moves from a loose to a tight culture s/he is confronted not only with value differences that give rise to discrepancies but also by the requirement that the latitude of acceptable behavior is not large, and this may be a direct threat to the individual's autonomy. By contrast, when the expatriate moves from a tight to a loose culture $\mathrm{s} / \mathrm{he}$ is confronted with discrepancies emanating from value differences and although s/he has a greater room to manoeuvre, s/he may yet experience disorientation due to a lack of structure. In sum, although value differences are the genesis of discrepancies between cultures, it is the tightness-looseness dimension that may determine how severe the discrepancies are, and the effectiveness of an individual's self-regulation strategies in coping with discrepancies.

\subsection{Promotion and prevention focused self-regulatory systems}

The self-regulatory systems (promotion and prevention) operate at three different levels, namely the system, strategic, and tactical (Johnson et al., 2015; Scholer \& Higgins, 2008). The system level describes the preference for the end states; the strategic level focuses on the means by which individuals seek to achieve their goals; whereas the tactical level describes the impact of the situational context on the decision made by the individuals.

At the systemic level, the promotion-focused self-regulatory system highlights the importance of nurturance needs, which are attained through growth and/or advancement 
(Righetti, Finkenauer, \& Rusbult, 2011; Lanaj et al., 2012). Growth and/or advancement means an upward shift from the existing status quo. It signifies progress or an improvement from the current condition. In order to accomplish this, promotion-focused expatriates are likely to pursue an eager strategy, which requires considering all possible options even if committing errors (Higgins, 1998; 1997). An eager strategy is an essential prerequisite for an upward shift although it does not necessarily imply that such a shift will necessarily occur. They are more positive towards change (Liberman, Idson, Camacho, \& Higgins, 1999) and are quicker to detect positive in any exchange relationship (Webber \& Mayer, 2011). Further, they tend to be more creative (Friedman \& Forster, 2001) and rely on feelings rather than reason in making decisions (Pham \& Avnet, 2004). This self-regulatory system also encourages entertaining multiple hypotheses (Liberman, Molden, Idson, \& Higgins, 2001) as the focus is on attaining hits than non-hits (Crowe \& Higgins, 1997). Although promotion focused individuals' value speed in decision-making they are somewhat slower in initiating action, relative to their prevention-focused counterparts (Freitas, Liberman, Salovey, \& Higgins, 2002). At a tactical level, individuals with a promotion focused self-regulatory system, may shift from a risky to a conservative bias depending upon situational constraints.

At a systemic level, the prevention-focused self-regulatory system is oriented towards an individual's security needs and it requires that individuals fulfill their duties and obligations by behaving vigilantly and responsibly (Righetti et al., 2011; Lanaj et al., 2012). At a strategic level, the strategy that they follow is one of accuracy (i.e., an absence of errors) and attaining a minimum level of performance (Forster, Higgins, \& Idson, 1998). Accuracy is important for the prevention focused individuals as they are not willing to accept a situation where they become worse of. It is for this reason that they resist change often preferring the status quo (Liberman, Idson, Camacho, \& Higgins, 1999), and find it difficult to build relationships (Webber \& Mayer, 2011; Das \& Kumar, 2011). Rigidity and a lack of creativity 
are also their hallmarks (Friedman \& Forster, 2001) and this follows from their preoccupation with avoiding committing any errors which may worsen their existing situation (Crowe \& Higgins, 1997). They are inclined to initiate goal-directed action much earlier than their promotion-focused counterparts (Freitas, Liberman, Salovey, \& Higgins, 2002). Given their emphasis on accuracy, prevention focused individuals are slow in their decision-making and their decision-making is shaped more by reasons than by feelings (Pham \& Avnet, 2004). At a tactical level they may shift from a conservative to a risky bias depending upon the situation. The promotion and the prevention regulatory foci are independent of each other rather than being at the opposite ends of a single continuum. It is important to note, however, that while both of the self-regulatory systems are available to an individual, “... there are chronic individual differences in the strength of each orientation and in how often each orientation is emphasized" (Higgins, 2012: 233). It is also important to note that a promotion focused selfregulatory system is more dominant in an individualistic culture whereas a prevention focused self-regulatory system is more dominant in collectivistic cultures.

\subsection{Regulatory fit}

Regulatory fit occurs when the strategy that individual uses to pursue a goal fits their regulatory orientation (Higgins, 2000). For example, if a promotion-focused individual engages in goal pursuit in an eager way then they are likely to experience regulatory fit. Likewise, if a prevention-focused individual pursues a goal through vigilance then they are likely to experience regulatory fit. Regulatory fit is associated with "increased motivational intensity" (Aaker \& Lee, 2006). Increased motivational intensity generates the experience of "feeling right" and the strength of engagement (Aaker \& Lee, 2006). The "feeling right" experience leads to greater confidence and may further enhance the importance of the goal that they are seeking to realize (Higgins, Idson, Freitas, Spiegel, \& Molden, 2003). The 
"feeling right" experience may amplify positive outcomes if initially positive and magnify negative outcomes if initially negative (Cesario, Grant, \& Higgins, 2004). This should translate into greater commitment and heightened confidence in their ability to realize those goals. The strength of engagement may also bridge the gap between implementation and action (Spriegel, Grant-Pillow, \& Higgins, 2004) as it enhances motivation towards accomplishing the goal.

\subsection{Promotion focused expatriate and the management of discrepancies}

A promotion focused expatriate's strategic orientation represents a fit with a loose culture and a non-fit with a tight culture. A promotion focused expatriate is concerned with growth and advancement and is willing to experiment to achieve his/her objectives. The desire to experiment is consistent with the norms prevalent in a loose culture where a large attitude in behaviors is permitted. A non-fit means that the strategies associated with the regulatory focus of the expatriate are inconsistent with what is required by the cultural norms prevalent in a tight culture. In contrast to a loose culture in a tight culture there is a narrow leeway of choice available to a promotion focused expatriate. The promotion focused expatriate may only have a narrow range of options to choose from. Accordingly, a promotion focused expatriate may feel overly constricted in terms of what s/he could do, and this may hinder his/her effectiveness. This may generate negative emotions (Tan, Hartel, Panipucci, \& Strybosch, 2005), call into question one's sense of identity (Lauring \& Selmer, 2009), and lead to a loss of face (Earley, 1997) for the expatriate. An absence of fit impacts interactional adjustment through the mediating role of emotions, face, and identity (Molinsky, 2007; Stoyanov, 2018). Next, we elaborate on the role of the mediating mechanisms in shaping expatriate adjustment. 


\section{Emotions}

Emotions are intense experiences of a short duration that are associated with physiological arousal and have a particular cause. Emotions impact behavior with different discrete emotions influencing behaviors differently (Barsade \& Gibson, 2007). Consider for example, the emotions of anger and fear. Anger arises in response to an act committed by another individual that is viewed as inappropriate, and it leads the individual to engage in approach behaviors while the emotion of fear arises out of a perceived threat and is often linked to escape or avoidance (Gooty, Gavin, \& Ashkanasy, 2003). Positive and negative emotions can be either functional or dysfunctional depending upon whether there is congruence between task requirements and the behavioral implications of the emotion (Weiss \& Cropanzano, 1996). Emotions influence the amount of effort that individuals exert on a given task, their persistence on the task, and/or their orientation towards the task, i.e., generative or defensive (Gu-Seo, Barrett, \& Bartunek, 2004).

A promotion focused self-regulatory system is focused on growth and accomplishment and this should generate cheerfulness related emotions such as happiness or satisfaction if a positive outcome has been attained and should generate dejection related emotions such as sadness, or disappointment with a negative outcome (Higgins, Shah, \& Friedman, 1997). Dejection-related emotions represent the absence of a positive outcome (Higgins, 1987). A prevention focused self-regulatory system is focused on safety and security and the goal here is to avoid a negative outcome. Prevention focus should generate a feeling of calm or a sense of relaxation in the absence of negative outcomes and should lead to anxiety or tension in the presence of a negative outcome (Higgins et al., 1997). Agitation related emotions represent the presence of a negative outcome (Higgins, 1987). For positive outcomes, the intensity of emotions experienced under a promotion-focused self-regulatory system is greater than that experienced under a prevention-focused self-regulatory system whereas for negative 
outcomes the intensity of emotions experienced under a prevention focused self-regulatory system is greater than that experienced under a promotion focused self-regulatory system (Brockner \& Higgins, 2001).

A promotion focused expatriate in a non-fit condition will experience dejection emotions for a multitude of reasons. The emergence of unfavorable discrepancies suggests, first of all, that the expatriate's attempt at dealing with work-related and interaction related issues are proving ineffective. This will generate negative emotions and, in particular, dejection related emotions, as these emotions are indicative of the expatriate's inability to achieve positive outcomes. The problem is likely to be compounded by the fact that the expatriate may have no clue as to how best to resolve the discrepancies that $\mathrm{s} / \mathrm{he}$ is confronted with. This may intensify the intensity of the negative emotions, as achieving a positive outcome seems quite distant. In sum, a promotion focused expatriate will be unable to realize their "ideals" for growth and accomplishment. This leads to the following proposition.

3.1 Proposition 1 - A promotion focused expatriate will experience dejection related emotions when seeking to cope with interactional related and work-related discrepancies in a tight culture.

Dejection related emotions lead the expatriate to intensify their efforts in attaining their goals. The danger is that in doing more of the same or even in experimenting the expatriate may end up creating an aggressive-defensive emotional cycle, which is negatively self-reinforcing (Kumar, 1997; 1999). Thus, an expatriate, who becomes dissatisfied and tries harder, may make the HCN more insecure and anxious, which in turn, may make the expatriate even more aggressive as the $\mathrm{HCN}$ seeks to withdraw from the interaction. In these circumstances, the psychological distance between the expatriates and the HCNs will increase. Accordingly, we propose that: 
3.2 Proposition 2 - In a non-fit condition, a promotion-focused expatriate has a greater likelihood of being caught up in an aggressive-defensive spiral when seeking to redress interactional discrepancies with HCNs.

Consider the challenges faced by Julie Nelson, General Manager of Alpha Gearing Systems (AGS) Shanghai in negotiating a contract in China (Everatt, 1999). AGS Shanghai Co Ltd was a joint venture between the US based company AGS and a Chinese company Kai Li Machine. AGS Shanghai hoped to sign an agreement with San Yu Moped, which was also a joint venture between the Chinese company San Yu, and a US based company Excel Motors. The negotiation process did not develop in a manner anticipated by Nelson and caused considerable aggravation to her. AGS was shipping parts to San Yu without a contractually agreed price but continued to do so on the assumption that relationship development is important in China. San Yu was tardy in payments to AGS and the account receivables for Alpha Shanghai continued to accumulate. After six months, San Yu informed AGS that they were still not willing to sign a long-term contract. AGS agreed to extend the contract by a further three months but when San Yu wanted a further extension. Julie Nelson finally lost her temper and told San Yu that no more parts would be shipped till they paid up. Nelson was slowly coming to the realization that this relationship was going nowhere and, acting on that basis, informed San Yu that they were dismantling their production lines that had been set up for San Yu.

Individualistic cultures are promotion focused and as a promotion-focused expatriate Julie Nelson was operating in the Chinese culture, which was tight (see for example Gelfand et al., 2011, 33 nation study). There is considerable evidence to suggest that collectivistic cultures are prevention focused whereas individualistic cultures are promotion focused (e.g., Higgins, Piero, \& Kruglanski, 2008). Individualistic cultures emphasize growth and 
advancement whereas collectivistic cultures emphasize duty and the fulfillment of one's obligations. Julie Nelson was in a non-fit situation in that she was unable to make any growth/advancement. The absence of a positive outcome led her to experience dejection related emotions such as anger, disappointment, and/or frustration. In trying to redress an actual-ideal outcome discrepancy, which is associated with a promotion-focused selfregulatory system Nelson undertook actions, which further strained the relationship between the parties (Everatt, 1999). She became aggressive and sent an ultimatum to San Yu knowing fully aware that this would not be acceptable in the Chinese cultural context. Although San Yu did not explicitly express their dissatisfaction to Julie Nelson, they did so indirectly by not redressing Julie Nelson's concerns and even when a last-ditch attempt was made by one of Alpha Shanghai's Chinese managers to persuade San Yu the latter did not respond positively. Next, "Face" is another variable that influences a promotion-focused expatriate's ability in building bridges with HCNs in a non-fit condition. Although face is not unique to Asian cultures many have noted its importance in such a cultural context (Kim \& Sam, 1998; Earley, 1997). Face is defined by Goffman and Erving (1955: 213) as "the positive social value a person effectively claims for himself by the line others assume he has taken during a particular contact. Face is an image of self-delineated in terms of approved social attributes" (see also Lockett, 1988's discussion on mianzi). Saving face is considered to be more critical than giving face in all cultures but in tight cultures the requirements for saving face and consequences of face loss are more stringent than in loose cultures (Kim \& Sam, 1998). It has been maintained that face is akin to a commodity during interaction as it "... can be threatened, enhanced, maintained, and bargained over" (Oetzel, Garcia, \& Toomey, 2008). The cognitive dimension focuses on how much face to give and how much to receive. The affective dimension highlights the emotional consequences of a loss or a gain in face whereas the behavioral dimension refers to the steps that need to be undertaken to both maintain and 
give face. Face negotiation theory (Ting-Toomey, 1988; Ting-Toomey \& Kurogi, 1998) suggests that face is the critical explanatory variable in conflict management. Face work becomes crucial because it is through this mechanism that the participants are able to either enhance their face, or support or question another's face (Ting-Toomey, 2005).

Eliminating interactional and work-related discrepancies that a promotion focused expatriate will encounter in a tight culture necessitates face work. However, this may not be easy for a promotion-focused expatriate in a non-fit condition. The strategies of creativity, flexibility, problem solving and/or willingness to take risks that such an expatriate prefers to follow may benefit the task but if they come at the expense of relational harmony then they may adversely impact both the other's face as well as one's own face. Relational harmony may be compromised for two fundamental reasons. First, the promotion focused expatriate is not likely to give it much importance relative to the task since their primary objective is about growth and accomplishment and not about the obligation to maintain social harmony. Furthermore, a focus on flexibility or creativity may necessitate experimentation, which may not be valued in a tight culture. Finally, in seeking to redress the actual-ideal outcome discrepancies they may be prone to overtly express their frustration and/or anger and this may not go down well in tight cultures where emotional suppression is the dominant norm (Matsumoto et al., 2008). This leads to the following proposition.

3.3 Proposition 3 - In a non-fit condition, a promotion-focused expatriate's interactional adjustment will be negatively impacted by causing a face loss to others and by a loss of one's own face.

Building on the previous example, Julie Nelson, the General Manager of AGS Shanghai faced this issue. San Yu managers liked to visit Shanghai and as per Chinese custom Julie Nelson should have entertained them lavishly and given that San Yu was potentially a 
major account for Alpha Shanghai. She did not do this, and this compromised her ability to foster a harmonious relationship with San Yu as face was not given to them. Nor did Julie Nelson take any other initiative to foster relationship with top managers at San Yu. Finally, when the problems became deeper her tone and actions became much more aggressive and pushed the relationship into a negative spiral placing relational harmony in further jeopardy.

A promotion-focused expatriate may also be confronted with an identity conflict when functioning in a tight culture. Identity conflict emerges “ "... when the behavioral demands of a situation make it impossible for an individual to behave both appropriately and in accordance with his or her core system of values" (Molinsky, 2007: 629). The greater the discrepancy norm, the greater is the possibility that the individual will experience such a conflict. Identity conflicts are problematical both because they challenge one's self-definition (Horton, Bayerl, \& Jacobs, 2003) and also because they activate group-based identities and in doing so establish a "group fault line” (Lau \& Murninghan, 1998). A classic in-group - out-group divide is created in which in-groups are viewed more favorably than the out-groups (Tajfel \& Turner, 1986). The bridging of differences then becomes problematical because as conflicts escalate so do negative emotions such as anger, anxiety and/or guilt (Meglino \& Ravlin, 1998). In addition to fostering the kind of negative conflict spiral that we eluded to earlier, negative emotions may also increase the 'psychological toll' the expatriate is confronted with (Molinsky, 2007). Psychological toll refers to the burdensome feeling that an expatriate may be subject to due to the presence of negative emotions. Psychological toll may make the expatriate exhausted and this may negatively impact his/her interactional adjustment. This leads to the following proposition. 
3.4 Proposition 4 - A promotion focused expatriate is likely to experience psychological toll when seeking to eliminate discrepancies in a tight culture, which may adversely impact his/her interactional adjustment.

As promotion focused expatriates seek to deal with interactional discrepancies, they will consider multiple options in redressing them. Prior research has demonstrated that promotion-focused individuals are willing to consider multiple options in problem resolution (Molden \& Higgins, 2008; Kurman \& Hui, 2012). The fact that a promotion focused individual is willing to consider new strategies to realize his/her goals is potentially beneficial but given the cultural gap between the promotion focus of the expatriate and the requirements of a tight culture, success is not necessarily assured. We would argue that $\mathrm{HCN}$ co-worker support would be critical in ensuring that the creativity and the flexibility of the expatriate is both well channeled and well received. Indeed, scholars have now suggested that HCN support is as critical to expatriate success as are the expatriates' own personal characteristics (Toh \& DeNisi, 2003). The HCNs provide critical information and support necessary for the expatriate to be highly effective, yet this support cannot be taken for granted. Much depends on whether the HCNs categorize the expatriate as being part of an in-group or the out-group (Toh \& DeNisi, 2007; Varma, Budhwar, \& Pichler, 2011; Varma, Budhwar, Katou, \& Mathew, 2016; Varma et al., 2006), and/or whether or not they are ethnocentric (Templer, 2010). Empathetic co-workers may respond positively to the expatriate's efforts as well as providing the relevant information that may be of benefit to the expatriate. At the same time the promotion focused expatriate must also be open and receptive to the advice of the HCNs and must interact with them in a manner that they feel comfortable giving the necessary advice. Although promotion focused individuals are open to considering new possibilities they may also be constrained by the strategy that their firm is pursuing. If the multinational firm is ethnocentrically driven, then even a promotion focused expatriate may be constrained 
in demonstrating the openness necessary for adaptation. This leads to the following proposition.

3.5 Proposition 5 - A promotion focused expatriate will consider multiple options in redressing interactional discrepancies but empathetic $\mathrm{HCN}$ co-workers may enhance the success of this strategy provided that the expatriate is both motivated to follow their advice and creates an environment for them to voice their opinion.

Julie Nelson could have solicited the advice of Chinese nationals working in the joint venture. At times the Chinese nationals in the joint venture did attempt to tell Julie that things in China are done differently but Julie Nelson appeared to be less than receptive and/or did not fully comprehend as to what is required (Everatt, 1999).

Black, Mendenhall and Oddou (1991) identify four work related factors that an expatriate has to deal with as s/he enters a new culture. These are role clarity, role discretion, role conflict, and role novelty. The authors suggest that role clarity facilitates expatriate adjustment as it reduces the level of uncertainty for the expatriate. Role discretion allows the individual to reshape the work role to suit their own needs rather than having to adapt to the situation. Role conflict will negatively impact expatriate adjustment as conflicting messages increase uncertainty. Role novelty also enhances uncertainty and would thus adversely affect expatriate adjustment. Tight cultures allow for little leeway in how things should be done. Norms may be tacit or explicit but there is likely to be clarity. Role clarity is thus likely to be high although the role discretion may be low given the imperatives of a tight culture. Role novelty may be high as how things are done in a tight culture may be rather distinct from how they are accomplished in a loose culture. A promotion focused expatriate who is used to operating in creative and innovative ways is likely to react negatively to the low level of role discretion as this might constrain him/her from being experimental and innovative in this 
domain. Although a promotion focused expatriate prefers novelty, a novel work assignment that might restrict his/her freedom of action is unlikely to be his/her preferred choice. Role conflict and role clarity may not be uniquely related to the tightness of a culture and hence we do not develop specific propositions about them. This leads to the following proposition.

3.6 Proposition 6 - A promotion focused expatriate's work-related adjustment would be negatively impacted by low role discretion in a tight culture.

Landmark studies by Tung $(1981 ; 1987)$ and later works (Black \& Stephens, 1989; Caliguiri \& Cascio, 1998; Shaffer \& Harrison, 1998) have demonstrated the influence of a spouse on expatriate's adjustment. The influence of a spouse on an expatriate's well-being and adjustment originate from spillover theory, which suggests that a working spouse's experiences will carry over into the home; likewise, home experiences can influence a person's work life (Crouter, 1984). Studies by Caliguiri et al. (1998) and Takeuchi, Yun and Tesluk (2002) found spillover effects of spouse on expatriate adjustment and vice versa, though the main concern in the literature has been on the potentially negative impact of spousal adjustment on expatriate performance.

Recent work has examined the impact of the spouse's regulatory focus on the individual's work-related adjustment and found that when both partners are high on promotion focus (fit) they experience higher developmental possibilities at home and have an increased likelihood of family-to-work facilitation (FWF) (Demerouti, Bakker \& Tetrick, 2012). In other words, regulatory fit between the partners is likely to have a positive impact on individual's work effectiveness. However, in the context of expatriate adjustment this logic may not necessarily hold. When the promotion focused expatriate is in a non-fit condition and when trying to redress interactional discrepancies and so is the spouse we have two cross cutting influences. On the one hand, the maladjustment of one may accentuate the 
maladjustment of the other as both are in a non-fit condition. The countervailing tendency is the fact that a high level of regulatory fit between the partners may moderate the negativity of cultural maladjustment. In other words, both may in turn support and comfort each other, which may lessen the negativity of their adjustment experience. Whether a similarity in regulatory fit is adaptive or maladaptive depends on the strength of their regulatory focus. If the strength of the regulatory focus is strong both for the expatriate and the spouse and when confronted with large interactional discrepancies, they will be highly motivated to resolve interactional discrepancies (Higgins, Shah, \& Friedman, 1997). This leads to the following proposition.

3.7 Proposition 7 - If both the expatriate and the spouse are promotion focused and are in a non-fit condition, then their cultural maladjustment may be lessened by the similarity in their regulatory focus orientation if both possess strong self-guides.

We have argued that in a tight culture a promotion focused expatriate will experience a non-fit which will hinder his/her adjustment absent an empathetic coworker and spousal support. Although this directional trajectory is fairly clear, it may also be the case that a nonfit condition provides new opportunities for learning and growth and growth and advancement and if the expatriate can overcome the initial challenges and control his/her emotions he/she may be able to learn and/or craft strategies for operating in a tight culture. This leads to the following proposition.

3.8 Proposition 8 - In a non-fit condition, a promotion focused expatriate may be successful in a tight culture if he/she has a high degree of emotional control.

\section{Prevention focused expatriate in a loose culture}


As a prevention focused expatriate enters a loose culture s/he will find that norms associated with interacting with HCNs are much looser than what they are used to. There is greater latitude of acceptable behavior. On the one hand this greater latitude implies a greater margin for committing errors and not being penalized. At the same time though the prevention focused expatriate has a greater need for structure, which will be absent in a loose culture (Gelfand et al., 2011). They are particularly concerned about behaving appropriately as they are very sensitive to fulfilling their duties and obligations (Higgins, 1997). The lack of structure heightens ambiguity and when confronted with an interactional discrepancy may need to think carefully as to how best to mitigate this. The ability to improvise and adapt to the local cultural norms may at the very least be a much slower process given their desire to prefer the status quo. A pre-eminent emphasis on safety discourages innovative behaviors and acts as a barrier against integrating in an effective manner with HCNs. Their aversion to ambiguity and a lack of clarity as to what is feasible is likely to generate agitation related emotions such as tension or anxiety. In a situation defined by an absence of structure it is not evident as to what are appropriate and what are inappropriate behaviors. This has the consequence that a prevention focused expatriated may commit errors and the possibility that this might happen generates agitation related emotions. This leads to the following proposition.

4.1 Proposition 9 - A prevention focused expatriate will experience agitation-related emotions in a non-fit condition.

Agitation-related emotions such as tension, fear, or anxiety may prompt an expatriate to withdraw from the interaction as these emotions are linked to a desire to escape. An escape may not be an easy option for two fundamental reasons. First, when an expatriate goes overseas s/he does so as part of a strategic assignment assigned to him by the organization. 
Expatriate assignments are costly, and an organization may not want to remove him in the first instance, the only caveat being if the initial assignment is itself of a shorter duration. Second, a prevention focused expatriate is guided by a sense of duty and obligation and even if not well adjusted may be reluctant to violate some of the obligations inherent in him having accepted the assignment. Furthermore, as the expatriate reflects on how best to interact with HCNs, a distance may emerge between him/her and the HCNs whereby the HCNs may begin to question the expatriate's slowness in adaptation. The initial cultural gap gets exacerbated by a behavioral inclination on part of the prevention-focused expatriate to be vigilant in his/her adaptive response. Accordingly, we propose proposition 10.

4.2 Proposition 10 - A prevention focused expatriate's emphasis on vigilance may lead to a defensive spiral in a non-fit condition, thus increasing rather than reducing the psychological distance between expatriates and HCNs.

Consider the strategic alliance between Business Software Solutions, a Kentucky based company and ABBA Deutschland of Stuttgart, Germany (Rarick, 2003). As part of this strategic alliance, the German company sent two expatriates (Hans Reinhardt and Wolfgang Reinhardt) to work in Kentucky. In terms of Gelfand's classification the German culture is more on the tighter end of the spectrum (average mean score for tightness is 6.5) whereas the American culture is more on the looser side. The German expatriates were troubled by what they perceived as a sense of casualness in terms of how things were done (people calling each other on a first name basis; individuals being assigned to lead a project whom they perceived as being immature). As a consequence, they retreated to safety by keeping their doors closed when not working. This did not go down well with their American counterparts who felt that the Germans were not friendly and in particular not keen on developing relationship with the Americans. Hans and Wolfgang were slow to adapt, and Wolfgang began to complain of 
allergies and headaches, which prevented him from coming to work from time to time. The German expatriates retreated into themselves, a behavioral mode consistent with a prevention focus orientation.

The prevention focused expatriate operating in a loose culture is less susceptible to face-related dynamics as the behavioral norms allow for greater flexibility in behavior. However, offending HCNs is one thing, and deepening a relationship with them a completely different proposition. While prevention focused expatriates may not offend the HCNs, they may not be able to deepen their relationship with them. Given their emphasis on vigilance, they will not share information easily or be accepting of information given to them by HCNs, because this makes them susceptible to HCNs who might be behaving opportunistically (Das \& Kumar, 2011). Furthermore, their reluctance to exchange information and to do it in a timely way will also act as a barrier to trust development (Das \& Kumar, 2011), which is vital if the relationship is to have any potential. This leads to the following proposition.

4.3 Proposition 11 - A prevention focused expatriate may hamper their interaction adjustment by a reluctance to exchange information sharing and/or being over vigilant by the information being given to them by their HCN counterparts.

Consider, once again the interactions between the Germans Hans and Wolfgang with their American counterparts. Colin Corum was leading a new project in the company and both Hans and Wolfgang were assigned to work with him. The Germans did not respect Colin because some of his habits were unconventional (Rarick, 2003) and this did not fit well with the tightness of the German culture. The interaction between Colin and Wolfgang did not develop well and neither liked each other very much. Sam asked Colin to improve his relationship with Wolfgang but that did not materialize. Sam was the supervisor of both 
Wolfgang and Hans and was surprised and saddened to learn that both had decided to return to Germany at the end of the year instead of finishing the two-year stint.

The prevention focused expatriate seeks to redress discrepancies in the interactional domain by persisting with a given course of action for a longer duration than might have been warranted otherwise (Kurman \& Hui, 2012). Persistence with and an ongoing reliance on the current option suggest an unwillingness to chart a new course in rectifying interactional related discrepancies. This could be problematical in the context of a loose culture where behavioral flexibility is highly valued as it is seen as instrumental to goal accomplishment. HCN co-worker support will be crucial in channeling the expatriate's efforts in a direction that are likely to rectify the discrepancies. Whether or not the $\mathrm{HCN}$ co-workers provide this support is dependent not only on how they categorize the expatriate but also on the expatriate's receptiveness to support from HCNs. The support from HCNs is critically dependent on whether or not their co-workers categorize them as being a member of the ingroup. If the expatriates are viewed as being part of the in-group they are likely to be afforded social support as well as being given the necessary information (Toh \& DeNisi, 2007; Varma et al., 2006; 2012). Also, empathetic co-workers may give information, and/or provide the support necessary for the expatriate to make the necessary adjustment. The willingness of a prevention focused expatriate to seek $\mathrm{HCN}$ support may also be in question, as they are highly vigilant. A heightened sense of vigilance suggests that they may be skeptical about the intentions of the HCNs. Based on the above discussion, we propose proposition 12.

4.4 Proposition 12 - A prevention focused expatriate will persist with a particular course of action in dealing with interactional related discrepancies, which may aggravate the expatriate's adjustment problem in the absence of HCN co-worker support. 
A prevention focused expatriate will need to deal with issues of role clarity, role discretion, role conflict, and role novelty (Black, Mendenhall, \& Oddou, 1991) as s/he enters a loose culture. In a loose culture, a prevention focused expatriate will be confronted with role novelty, a lack of role clarity, a high level of role discretion, and clearly the possibility of role conflict. Role novelty is likely to be high as there is greater variation in how things are accomplished in a loose culture as opposed to a tight culture. Role clarity may also be low given the lack of structure in this environment and this may be coupled with a higher level of role discretion than what the expatriate may have been used to. A prevention focused expatriate who is used to operating in a structured manner may react negatively to a lack of role clarity and a high level of role discretion as this offers the possibility that s/he might commit a mistake which s/he abhor intensely. This leads to the following proposition.

\subsection{Proposition 13 - A prevention focused expatriate's adjustment will be negatively} impacted by a high level of role discretion, and a lack of role clarity.

Expatriates also face the challenge of motivating their subordinates in an environment that is alien to them. Organizational scholars have begun to highlight the importance of organizational citizenship behaviors (OCB) and team specific human capital in shaping an organization's performance (e.g., Gerrard \& Lockett, 2018). OCBs are behaviors performed by employees that go beyond the call of duty and may enhance an organization's effectiveness (Borman \& Motowildo, 1993). Engaging in OCB behaviors “... is a goal driven, adaptive behavior, which is strongly affected by employee's motivation and regulatory processes" (Shin et al., 2017: 2). Interpersonal regulatory fit theory posits that a fit between an individual's regulatory orientation and that of his/her interaction partners determines the latter's motivation in pursuing specific goals (Righetti et al., 2011). It has been noted, for example, that transformational leadership was more motivating for individuals who possessed 
a promotion as opposed to prevention focused self-regulatory system (Benjamin \& Flynn, 2006). Likewise, Venus, Stam and Von Knippenberg (2013) demonstrated that the performance of individuals was enhanced when their regulatory focus was consistent with the manner in which the leader communicated the vision. A key implication of all of this is that an expatriate's ability to motivate his/her employees is critically dependent on the compatibility between the expatriate's self-regulatory orientation and that of his/her employees. Shin et al. (2017) tested the impact of the compatibility between the leaders and the followers' self-regulatory orientation on the propensity to engage in OCBs. Their study demonstrated that the impact of interpersonal regulatory fit was stronger for prevention as opposed to a promotion focus self-regulatory system. In other words, leaders that pursue leadership focusing on duties and obligations encourage their prevention-oriented followers to engage in greater prosocial behavior. This leads to the following proposition:

4.6 Proposition 14 - A prevention focused expatriate is likely to encourage his /her prevention focused followers to pursue OCBs.

Next, as we noted earlier, the literature on expatriate failures and, more specifically, premature return has emphasized the role of the expatriate's spouse (e.g., Black \& Stephens, 1989). While spousal disagreements might arise from any number of diverse sources, e.g., whether or not the spouse is allowed to work in the host country, whether or not s/he finds suitable social networks, etc., a difference in regulatory foci can also lead to spousal conflict. Thus, if the expatriate and his/her spouse are both prevention focused, then, as Demerouti et al. (2012) suggest, there is likely to be less family to work conflict. The spillover effects from the family to the work domain will not be negative and this should leave the expatriate in a better frame of mind in the new cultural milieu. However, if both the expatriate and the spouse are in a non-fit condition, then the maladjustment of one will further aggravate the maladjustment of the other. This leads to the following proposition. 
4.7 Proposition 15 - If both the expatriate and the spouse are prevention focused and are in a non-fit condition then their cultural maladjustment will be enhanced. However, the lower the family to work conflict, the less intense such a maladjustment might be.

We have argued that in a loose culture a prevention focused expatriate will be subject to a non-fit which will impede adjustment unless an empathetic coworker is present and there is the presence of spousal support. Although this directional path is clear, it may also be the case that a non-fit condition motivates the prevention focused expatriate to do whatever he/she can to avoid a situation where a non-fit emerges. This may lead the prevention focused expatriate to prepare as thoroughly as he/she possibly could prior to entering a loose culture. This leads to the following proposition.

4.8 Proposition 16 - In a non-fit condition a prevention focused expatriate may be successful in a loose culture if he/she is well prepared for the assignment.

\section{Conclusions}

The paper explores how the process of expatriates' self-regulation influences their adjustment in a novel cultural context. It is widely recognized that when expatriates are transplanted into unfamiliar cultural environments, they are confronted with discrepancies in the domains of interaction, work, and/or general adjustment (Black et al., 1991). In this paper, we focus on interactional and work-related discrepancies and propose that expatriate adjustment depends on whether or not there is a fit between the expatriate's self-regulatory system and the nature of the culture (tight vs. loose). We propose that an expatriate with a promotion focused self-regulatory system will experience non-fit in a tight culture. and an expatriate with a prevention focused self-regulatory system will experience non-fit in a loose 
culture. Non-fit gives rise to emotions, and negative spirals, all of which will adversely impact on the expatriate's adjustment. The presence of regulatory fit, by contrast, strengthens engagement, which should improve an expatriate's performance (Lazarova, Westman, \& Shaffer, 2010; Varma et al., 2011). In drawing upon the concept of regulatory-fit (Higgins, 2000), we are drawing upon recent advances in motivational theory to explain expatriate performance.

We believe that the proposed framework enriches and advances expatriate research on a number of dimensions. Scholars are now beginning to recognize the importance of motivational processes in shaping expatriate performance (Lazarova et al., 2010), but the existing literature has paid insufficient attention to issues of intra personal motivation. We propose that to understand the motivational dynamics of expatriate adjustment it is imperative to draw upon regulatory focus theory, which is generating considerable interest. The model proposes two alternative self-regulation systems, namely a promotion and a prevention focused.

A further contribution of the paper is a more explicit focus on the role of emotions in expatriate intercultural encounters. Emotions are inevitable whenever discrepancies arise (Mandler, 1975) and while the occurrence of emotions is a theme that is often mentioned in expatriate research, scholars have as yet to draw a distinction between the different classes of negative emotions (dejection vs. agitation) (Higgins, 1987) and how they might influence expatriate's interactional adjustment. We believe that this is a notable omission as not all types of negative emotions have similar behavioral consequences (for example anger is linked to aggression and fear to escape). The idea that expatriates experience negative emotions in an alien cultural environment may be insufficiently developed and the framework, which is being offered in this paper, provides a new area of inquiry. 
The paper also suggests that a promotion focused expatriate will consider multiple options and will be more willing to experiment with new strategies. Such an expatriate is likely to engage in what Ren et al. (2014) describe as "proactive embedding" which entails the search for new information, developing relationships, and positive framing. Although these attributes may facilitate adjustment, one of the challenges that even promotion focused expatriates may face is that they may not know what strategy the best for them might be. Coworker support will be critical in enabling this to happen. The prevention focused expatriate will, by contrast, single-mindedly and doggedly pursue the same strategy that they have previously pursued, and even if they do change their strategy it will be a long time in coming. This expatriate will need to be gently nudged to change course and be provided with the appropriate support through HCN co-workers.

The theory being advanced here has important implications for human resource managers in a multinational firm. The first implication is that managers being considered for an overseas assignment and their spouses should be assessed on their regulatory focus (promotion vs. prevention focused) and a determination made as to whether or not a fit exists between their self-regulation system and the characteristics of the culture to which they are being assigned (tight vs. loose). This will help the multinational to more effectively screen people for their suitability for the assignment. A number of measures of regulatory focus are now available (e.g., Lockwood, Jordan, \& Kunda, 2002) which can be used to make such a determination and a preliminary typology of tight and loose cultures have now been developed by Gelfand et al. (2011). Further, while many multinational firms now provide predeparture training to orient the expatriate and his/her family to the novel cultural environment, it is unlikely that this training directly addresses the expatriate's self-regulatory system, which serves as the anchor for decision-making. Existing models of expatriate training highlight the cultural distance that expatriates face when moving to a new assignment. They may also 
provide generic strategies for coping with the cultural distance, but few explore the linkage between the regulatory focus of the expatriate and the strategy that might work best for him/her. The model of training that we advocate would take that extra step and in doing so provide a new approach for expatriate training. The expatriates can be measured on their regulatory focus prior to training and during the training session can be debriefed on their dominant motivational approach. This will help them to gain that self-knowledge which will be useful when functioning in a new culture.

Expatriates may acquire a lot of knowledge about foreign cultures, but unless they have a good understanding of how their own motivational systems work. they will remain ignorant of their own inner biases and emotions that are shaping their judgments and behaviors. Further, while we would suppose that multinationals and many HR managers are cognizant of the stresses and strains that an expatriate may be exposed to, they may not know precisely what kind of emotions might be experienced by the expatriates. As such, we believe that delving into the inner emotional dynamics is quite critical, as different emotions are indicative of different kinds of issues that an expatriate may be dealing with.

The theoretical framework that we advance in this paper can be extended in a number of different directions. In this paper, we look primarily at how the expatriate's self-regulatory system influences the way they manage interactional discrepancies. We develop a number of propositions that are amenable to empirical testing. Expatriates could be assessed on their regulatory focus with a number of validated measures being currently available and their performance tracked over time in the cultural context (tight vs. loose) where they are currently working. Spouses and co-workers could also be assessed on the same dimensions to assess the impact of congruent and incongruent foci on an expatriate's interactional adjustment. In order to conduct meaningful empirical investigation, we present: 1) sources of 
measures of our core research constructs, and 2) a suitable methodology to conduct a robust analysis.

\subsection{Measures of core constructs}

Individual and spouse regulatory focus can be measured using two scales, the regulatory focus questionnaire (RFQ, Higgins et al., 2001) and the general regulatory focus measure (GRFM, Lockwood et al., 2002), that dominate the literature. The RFQ has been shown to predict emotional outcomes, such as guilt and coping (e.g., Camacho, Higgins, \& Luger, 2003), cognitive outcomes such as persuasion and language use (e.g., Semin, Higgins, de Montes, Estourget, \& Valencia, 2005) and both mental and physical health outcomes (e.g., Strauman et al., 2006).

The tight versus loose construct can be measured using Gelfand et al. (2011) generalized measure of tightness-looseness that assesses the degree to which social norms are pervasive, clearly defined, and reliably imposed within nations. Expatriate adjustment can be measured using a combination of scales put forth by Black and Gregersen (1991), Shaffer, Harrison and Gilley (1999), Caliguiri (1997) and Kraimer and Wayne (2004).

\subsection{Suggestions for empirically testing our model}

In the context of our model the regulatory focus of expatriate in conjunction with the cultural context (tight versus loose) may be most important in determining whether or not there is regulatory fit (in stage two of the process). Thus, if the fit exists, then managing interactional related discrepancies will be less of an issue but in the absence of expatriate's fit, if the spouse shows adequate fit then the problems may be mitigated by due to the spillover effect. However, this is contingent on the strength of the regulatory focus of the expatriate and his/her spouse. Therefore, careful consideration of such interpersonal mechanisms by 
incorporating several viewpoints, i.e., expatriates, spouse and co-worker support within and across process stages will allow future studies to appropriately reflect the mutuality of the regulatory formation process.

Any full quantitative examination of our model must also incorporate a longitudinal design. Tracking expatriates' regulatory formation processes, starting from their arrival in the host country, will involve periodic measurements of variables as well as input from spouse and co-workers. It may also be advantageous to measure expatriate's adjustment overtime, perhaps using growth curve modeling, to determine the extent to which regulatory focus actually increases adjustment process and the points at which it does so. Co-worker support ties that are based on emotional support, trust and affect may require more time to develop. Thus, in future studies researchers may need to adjust their observations on the basis of type of co-worker support and regulatory focus strategies. Researchers may also employ qualitative studies such as scenario methods or diary studies to capture the full range of such interpersonal events that leads to the formation of regulatory strategies by expatriates over time.

It is our considered view that the regulatory focus theory, and the concept of regulatory fit, offer a new and a powerful lens for understanding the dynamics of expatriate adjustment. Adjustment is a dynamic process in which the expatriates' cognitions and emotions play an influential role in determining how the process unfolds. We are well cognizant of the challenges that the expatriates face, but we know relatively less about how they cope with the discrepancies that they are confronted with. This paper provides the impetus for beginning research in a relatively unexplored domain of expatriate adjustment and we hope that researchers will build on this to deepen our understanding of the motivational processes that underlie expatriate adjustment. 


\section{References}

Aaker, J.L., \& Lee, A.Y. (2006). Understanding regulatory fit. Journal of Marketing Research, XLIII, 15-19.

Ang, S., Van Dyne, L., Koh, C.K.S., Ng, K.Y., Templer, K.J., Tay, C., \& Chandrasekar, N.A. (2007). Cultural intelligence: Its measurement and effects on cultural judgment and decisionmaking, cultural adaptation, and task performance. Management and Organization Review, 3, 335-371.

Appelt, K.C., \& Higgins, E.T. (2010). My way: How strategic preferences vary by negotiator role and regulatory focus. Journal of Experimental Social Psychology, 46, 1138-1142.

Ashkanasy, N.M. (2003). Emotions in organizations: A multi- level perspective. Research in Multi-Level Issues, 2, 9-54.

Aycan, Z., Kanungo, R.N., \& Sinha, J.B.P. (1999). Organizational culture and human resource management practices. The model of culture fit. Journal of Cross Cultural Psychology, 30, 501-526.

Barsade, S., \& Gibson, D.E. (2007). Why does affect matter in organizations? Academy of Management Perspectives, 21:36-59.

Baumeister, R.F., Heatherton, T.F., \& Tice, D.M. 1993. When ego threats lead to selfregulation failure: Negative consequences of high self-esteem. Journal of Personality and Social Psychology, 64,141-156.

Benjamin, L., \& Flynn, F.J. (2006). Leadership style and regulatory mode: Value from fit? Organizational Behavior and Human Decision Processes, 100, 216-230.

Berry, J.W., \& Kailin, R. (1995). Multicultural and ethnic attitudes in Canada: An overview of the 1991 national survey. Canadian Journal of Behavioral Sciences, 27, 301-320.

Bhaskar-Shrinivas, P., Harrison, D. A., Shaffer, M. A., \& Luk, D. M. (2005). Input-based and time-based models of international adjustment: Meta-analytic evidence and theoretical extensions. Academy of Management Journal, 48(2), 257-281.

Black, J.S., \& Gregersen, H. (1991). The other half of the picture: Antecedents of spouse cross cultural adjustment. Journal of International Business Studies, 22, 461-477.

Black, J.S., Mendenhall, M., \& Oddou, G. (1991). Toward a comprehensive model of international adjustment: An integration of multiple theoretical perspectives. Academy of Management Review, 16, 291-317.

Black, J.S., \& Stephens, G.K. (1989). The influence of the spouse on expatriate adjustment and intent to stay in Pacific Rim assignments. Journal of Management, 15: 529-544.

Borman, W.C., \& Motowidlo, S.J. (1993). Expanding the criterion domain to include elements of contextual performance. In N. Schmitt \& W.C. Borman (Eds.) Personnel selection in organizations. 349-381. San Francisco: Jossey Bass.

Bowler, W.M., Halbesleben, J.R., \& Paul, J.R. (2010). If you're close with the leader, you must be a brownnose: The role of leader member relationships in follower, leader, and 
coworker attributions of organizational citizenship behavior motives. Human Resource Management Review, 20, 309-316.

Brindle, M., \& Higgins, E.T. (1996). Principles of judging valence: What makes events positive or negative? Advances in Experimental Social Psychology, 28, 95-160.

Budhwar, P., \& Sparrow, P. (2002). Strategic HRM through the cultural looking glass: Mapping cognitions of British and Indian HRM managers. Organization Studies, 23: 599638.

Bulow, A.M., \& Kumar, R. (2011). Introduction to the special issue on cross cultural negotiations. International Negotiation Journal, 16, 349-359.

Cesario, J., Grant, H., \& Higgins, E.T. (2004). Regulatory fit and persuasion: Transfer from "feeling right". Journal of Personality and Social Psychology, 86, 388-404.

Caligiuri, P. \& Cascio, W. (1998). Can we send her there? Maximizing the success of Western women on global assignments. Journal of World Business, 33, 394-416.

Caliguiri, P., Hyland, M.A M., \& Bross, A.S. (1998). Testing a theoretical model for examining the relationship between family adjustment and expatriates work adjustment. Journal of Applied Psychology, 83, 598-614.

Camacho, C. J., Higgins, E. T., \& Luger, L. (2003). Moral value transfer from regulatory fit: What feels right is right and what feels wrong is wrong. Journal of Personality and Social Psychology, 84: 498-510.

Chan, D.K.S., Gelfand, M.J., Triandis, H.C., \& Zeng, O. (1996). Tightness and looseness revisited: Some preliminary analysis in the United States and Japan. International Journal of Psychology, 31, 1-12.

Chua, R.Y.J., Roth, Y., \& Lemoine, J.F. (2015). The impact of culture on creativity: How cultural tightness and cultural distance affect global innovation crowdsourcing work. Administrative Science Quarterly, 60, 189-227.

Costa, P.T., \& McRae, R.R. (1992). Normal personality assessment in clinical practice: The NEO personality inventory. Psychological Assessment, 4, 5-13.

Crouter, A. (1984). Spillover from family to work: The neglected side of the work-family interface. Human Relations, 37, 425-442.

Chatman, J.A. (1989). Improving interactional organizational research: A model of personorganization fit. Academy of Management Review, 14, 333-349.

Crowe, E., \& Higgins, E.T. (1997). Regulatory focus and strategic inclinations: Promotion and prevention in decision making. Organizational Behavior and Human Decision Processes, 69, 117-132.

Das, T.K., \& Kumar, R. (2011). Regulatory focus and opportunism in the alliance development process. Journal of Management, 3, 672-708.

Demerouti, E., Bakker, A.B., \& Tetrick, L.E. (2012). Regulatory focus and the family-work interface: The role of regulatory fit between cohabiting partners. European Journal of Work and Social Psychology, 1-13 
Diefendorff, J.M., \& Greguras, G.J. (2009). Contextualizing emotional display rules: Examining the roles of targets and discrete emotions in shaping display rule perceptions. Journal of Management, 35, 880-898.

Earley, P.C., \& Ang, S. (2003). Cultural Intelligence: Individual interaction across cultures. Stanford Business Books, Palo Alto, CA.

Earley, P.C. (1997). Face, harmony, and social structure: An analysis of organizational behavior across cultures. Oxford: Oxford University Press.

Elfenbein, H. (2007). Emotion in organizations: A review and theoretical integration. The Academy of Management Annals, 1, 315-386.

Elliot, A.J., \& Thrash, T.M. (2002). Approach-avoidance motivation in personality: Approach and avoidance temperaments and goals. Journal of Personality and Social Psychology, 82, 804-818.

Erez, M., \& Earley, P.C. (1987). Comparative analysis of goal- setting strategies across cultures. Journal of Applied Psychology, 72, 658-665.

Everatt, D. 1999. Alpha Gearing Systems Shanghai Co., Ltd. Cranfield, UK: The Case Center.

Fang, Y., Jang, G.L. F., Makino, S., \& Beamish, P.W. (2010). Multinational firm knowledge, use of expatriates, and foreign subsidiary performance. Journal of Management Studies, 47, 27-54.

Forster, J., \& Higgins, E.T. (2005). How global vs. Local perception fits regulatory focus. Psychological Science, 16, 631-636.

Freitas, A.L., Liberman, N., \& Higgins, E.T. (2002). Regulatory fit and resisting temptation during goal pursuit. Journal of Experimental Social Psychology, 38, 291-298.

Frijda, N.H. (1986). The emotions. Cambridge: Cambridge University Press.

Gelfand, M.J. (2012). Culture's constraints: International differences in the strength of social norms. Current Directions in Psychological Science, 21, 420-424.

Gelfand, M.J., Raver, J.L., Nishii, L., Leslie, L.M., Lun, J., Lim, B.C., ..... Yamaguchi, S. (2011). Differences between tight and loose cultures. Science, 332, 1100-1104.

Gelfand, M.J., Nishii, L.H., \& Raver, J.L. (2006). On the nature and importance of cultural tightness-looseness. Journal of Applied Psychology, 91, 1225-1244.

Gerrard, B., \& Lockett, A. (2018). Team-specific human capital and performance. British Journal of Management, 29(1), 10-25.

Goffman \& Erving, (1955). On face-work: An analysis of ritual elements of social interaction. Psychiatry: Journal for the Study of Interpersonal Processes 18(3), 213-231.

Gooti, J., Gavin, M., \& Ashkanasy, N.M. (2009). Emotions research in OB: The challenges that lie ahead. Journal of Organizational Behavior, 30, 833-838.

Higgins, E.T. (1987). Self- discrepancy: A theory relating self and affect. Psychological Review, 94, 319-340.

Higgins, E.T. (1997). Beyond pleasure and pain. American Psychologist, 52, 1280-1300. 
Higgins, E.T. (1998). Promotion and prevention: Regulatory focus as a motivational principle. Advances in Experimental Social Psychology, 30, 1-46.

Higgins, E.T. (2000). Making a good decision: Value from fit. American Psychologist, 55, 1217-1230.

Higgins, E.T. (2005). Value from regulatory fit. Current Directions in Psychological Science, $14,209-213$.

Higgins, E.T., Idson, L.C., Freitas, A.L., Spriegel, S., \& Molden, D.C. (2003). Transfer of value from fit. Journal of Personality and Social Psychology, 84, 1140-1153.

Higgins, E.T., Ronald S. Friedman, R.S., Harlow, R.E., Idson, L.C., Ayduk, O.N. \& Taylor, A. (2001). Achievement orientations from subjective histories of success: promotion pride vs prevention pride. European Journal of Social Psychology, 31, 3-23.

Higgins, E.T., Pierro, A., \& Kruglanski, A.W. (2008). Rethinking culture and personality: How self regulatory universal create cross cultural differences. In R.M. Sorrentino \& S. Yamaguchi (Eds.) Handbook of motivation and cognition across cultures (pp. 161-190). New York, NY: Elsevier.

Higgins, E.T. (2010). Beyond pleasure and pain: How motivation works. Oxford: Oxford University Press.

Hofstede, G. (1991). Cultures and organizations: Software of the mind. New York: McGraw Hill.

Horton, K.E., Bayerl, P.S., \& Jacobs, G. (2014). Identity conflicts at work: An integrative framework. Journal of Organizational Behavior, 35, S6-S22.

House, R.J., Hanges, P.J., Javidan, M., \& Dorfman, P.W., \& Gupta, V. (2004). Culture, leadership, and organizations: The Globe study of 62 cultures. Sage: San Francisco

Johnson, P.D., Smith, M.B., Wallace, J.C., Hill, A.D., \& Baron, R.A. (2015). A review of multi level regulatory focus in organizations. Journal of Management, 41, 1501-1529.

Jones, G. R., \& George, J. M. (1998). The experience and evolution of trust: Implications for cooperation and teamwork. Academy of Management Review, 23, 531-546.

Kark, R., \& Van Dijk, D. (2007). Motivation to lead, motivation to follow: The role of selfregulatory focus in leadership processes. Academy of Management Review, 32, 500-528.

Karoly, P. (1993). Mechanisms of self-regulation: A systems view. Annual Review of Psychology, 44, 23-52.

Kim, J.Y., \& Sam, S.H. (1998). The concept and the dynamics of face: Implications for organizational behavior in Asia. Organization Science, 9, 522-534.

Klodinia, L., \& Johnson, R.E. (2012). Regulatory focus and work-related outcomes. Psychological Bulletin, 138, 938-1034.

Kraimer, M.L., \& Wayne, S.J. (2004). An examination of perceived organisational support as a multidimensional construct in the context of an expatriate assignment. Journal of Management, 30, 209-237. 
Kumar, R. (1999). Communicative conflict in intercultural negotiations: The case of American and Japanese business negotiations. International Negotiation Journal, 4, 63-78.

Kumar, R. (1997). The role of affect in negotiations: An integrative overview. Journal of Applied Behavioral Science, 33, 84-100.

Kurman, J., \& Hui, C.M. (2012). Cultural regulatory fit and strategies for coping with unsuccessful outcomes. European Journal of Social Psychology, 42, 482-489.

Lanaj, K., Chang, C.H.D., \& Johnson, R.E. (2012). Regulatory Focus and work-related outcomes: A review and meta-analysis. Psychological Bulletin, 138, 998-1034.

Lauring, J., \& Selmer, J. (2009). Expatriate compound living: An ethnographic field study. International Journal of Human Resource Management, 7, 1451-1467.

Lawler, E. J., \& Thye, S. R. (1999). Bringing emotions into social exchange theory. Annual Review of Psychology, 25, 217-244.

Lazarova, M., Westman, M., \& Shaffer, M.A. (2010). Elucidating the positive side of the work family interface on international assignments: A model of expatriate work and family performance. Academy of Management Review, 35, 93-117.

Lazarus, R. (1991). Emotion and adaptation. New York: Oxford University Press.

Lee, C.H., Hung, C.C., Chien, C.S., Zhuang, W.L., \& Hsu, C.Y.Y. (2017). Regulatory foci and expatriate adjustment. Personnel Review, 46: 512-525.

Lee, Y.T., \& Antonakis, J. (2014). When preference is not satisfied but the individual is: How power distance moderates person-job fit. Journal of Management, 40, 641-675.

Liberman, N., Idson, L.C., Camacho, C.J., \& Higgins, E.T. (1999). Promotion and prevention: Choices between stability and change. Journal of Personality and Social Psychology, 77, $1135-1145$

Lockett, M. (1988). Culture and the problems of Chinese management. Organization Studies, 9(4), 475-496.

Lockwood, P., Jordan, C.H., \& Kunda, Z. (2002). Motivation by positive or negative role models: Regulatory focus determines who will best inspire us. Journal of Personality and Social Psychology, 83, 854-864.

Mandler, G. (1975). Mind and emotion. New York: Wiley.

Matsumoto, D., Yoo, S.H., Nakagawa, S., \& 37 members of the multinational study of cultural display rules. (2008). Culture, emotion regulation, and adjustment. Journal of Personality and Social Psychology, 94, 925-937.

Meglino, B.M., \& Ravlin, E.C. (1998). Individual values in organizations: Concepts, controversies, and research. Journal of Management, 24, 251-289.

Minov, M., Blagoev, V., \& Hofstede, G. (2012). The boundaries of culture: Do questions about societal norms reveal cultural differences? Journal of Cross Cultural Psychology, 1-13.

Molden, D.C., \& Hui, C.M. (2011). Promoting de-escalating of commitment: The regulatory focus perspective on sunk costs. Psychological Science, 22, 8-12. 
Molden, D.C., \& Higgins, E.T. (2008). How preference for eager versus vigilant judgment strategies affect self-serving conclusions. Journal of Experimental Social Psychology, 44, 1219-1228.

Molinsky, A. (2007). Cross-cultural code-switching: The psychological challenges of adapting behavior in foreign cultural interactions. Academy of Management Review, 32, 622640.

Mossholder, K.W., Richardson, H.A., \& Setton, R.P. (2011). Human resource systems and helping in organizations: A relational perspective. Academy of Management Review, 36, 3352.

Nguyen, H., Johnson, A., Collins, C., \& Parket, S. (2017). Confidence matters: Self-efficacy moderates the credit that supervisors give to adaptive and proactive role behaviours. British Journal of Management, 28(2), 315-330.

Oetzel, J., Garcia, A.J., \& Toomey, S.T. (2008). An analysis of the relationships among face concerns and facework behaviors in perceived conflict situations: A four culture investigation. International Journal of Conflict Management, 19, 382-403.

Pelto, P. (1968). The difference between 'tight' and 'loose' societies. Transaction, 5, 37-40.

Pham, M., \& Avnet, T. (2004). Ideals and oughts and the reliance on affect versus substance in persuasion. Journal of Consumer Research, 30, 503-518.

Rarick, C.A. (2003). Hans and Wolfgang experience American culture. Cranfield, UK: European Case Clearing House.

Richards, D. (1996). Strangers in a strange land: Expatriate paranoia and the dynamics of exclusion. International Journal of Human Resource Management, 7, 553-571.

Ren, H., Shaffer, M.A., Harrison, D.A., Fu, C., \& Fodchuk, K.M. (2014). Reactive adjustment or proactive embedding: Multistudy, multiwave evidence for dual pathways to expatriate retention. Personnel Psychology, 67, 203-239.

Righetti, F., Finkenauer, C., \& Rusbult, C. (2011). The benefits of interpersonal regulatory fit for individual goal pursuit. Journal of Personality and Social Psychology, 101, 720-736.

Scholer, A.A., \& Higgins, E.T. (2008). Distinguish levels of approach and avoidance: An analysis using regulatory focus theory. In A.J. Elliot (Ed.) Handbook of approach and avoidance motivation (pp. 489-503). New York, NY: Psychology Press.

Semin, G.R., Higgins, E.T., de Montes, L.G., Estourget, Y., \& Valencia, J.F. (2005). Linguistic signatures of regulatory focus: How abstraction fits promotion more than prevention. Journal of Personality and Social Psychology, 89, 36-45.

Shaffer, M.A., Reiche, S.B., Dimitrova, M., Lazarova, M., Chen, Shoshi., Westman, M., and Wurtz, O. (2016). Work-and family-role adjustment of different types of global professionals: Scale development and validation. Journal of International Business Studies, 47, 113-139.

Shaffer, M. A., \& Harrison, D. A. (1998). Expatriates' psychological withdrawal from international assignments: Work, non-work, and family influences. Personnel Psychology, 51, 87-118. 
Shaffer, M.A., Harrison, D.A., \& Gilley, K.M. (1999). Dimensions, determinants and differences in the expatriate adjustment process. Journal of International Business Studies, $30,557-581$.

Shaw, J. B. (1990). A cognitive categorization model for the study of intercultural management. Academy of Management Review, 15, 636-646.

Shin, Y., Kim, M.S., Choi., J.N., Kim, M., \& Won- Kyung, O. (2017). Does leader follower regulatory fit matter? The role of regulatory fit in followers' organizational citizenship behaviors. Journal of Management, 43(4), 1211-1233.

Silbiger, A., Berger, R., Narnes, B.R., \& Renwick, D.W.S. (2017). Improving expatriation success: The roles of regulatory focus and burnout. British Journal of Management, 28(2), 231-247.

Spiegel, S., Grant-Pillow, H., \& Higgins, E.T. (2004). How regulatory fit enhances motivational strength during goal pursuit. European Journal of Social Psychology, 34, 39-54.

Strauman, T.J., Veith, A.Z., Merril, K.A., Kolden, G.G., Woods, T.E., Klein, M.H., et al. (2006). Self-system therapy as an intervention for self-regulatory dysfunction in depression: A randomized comparison with cognitive therapy. Journal of Counselling and Clinical Psychology, 74, 367-376.

Stea, D., Pedersen, T., \& Foss, N.J. (2017). The relational antecedents of interpersonal helping: 'Quantity', 'quality' or both? British Journal of Management, 28(2), 197-212.

Stoyanov, S. (2018) Enabling social identity interaction: Bulgarian migrant entrepreneurs building embeddedness into a transnational network. British Journal of Management, 29(2), 373-388.

Tajfel, H., \& Turner, J.C. (1986). 'The social identity theory of intergroup behavior' in S. Worchel \& W.G. Austin (Ed) Psychology of intergroup relations Chicago, Illinois: NelsonHall.

Takeuchi, R. (2010). A critical review of expatriate adjustment research through a multiple stakeholder view: Progress, emerging trends, and prospects. Journal of Management, 36, 1040-1064.

Takeuchi, R., Wang, M., Marinova, S., \& Yao, X. (2009). The role of domain- specific perceived organizational support during expatriation and their implications for performance. Organization Science, 20, 621-634.

Takeuchi, R., Shay, J.P., \& Li, J.T. (2008). When does decision autonomy increase expatriate adjustment: An empirical test. Academy of Management Journal, 51, 45-60.

Takeuchi, R., Wang, M., \& Marinova, S.V. (2005). Antecedents and consequences of psychological workplace strain during expatriation: A cross sectional and longitudinal investigation. Personnel Psychology, 58, 925-948.

Takeuchi, R., Yun, S., \& Tesluk, P.E. (2002). An examination of crossover and spillover effects of spousal and expatriate cross- cultural adjustment on expatriate outcomes. Journal of Applied Psychology, 87, 655-666.

Tan, J.A.C., Hartel, C.E.J., Panipucci, D., \& Strybosch, V.E. (2005). The effect of emotions in cross-cultural expatriate experiences. Cross Cultural Management, 12, 4-15. 
Taras, V., Kirkman, B.L., \& Steel, P. 2010. Examining the impact of Culture's Consequences: A three decade, multilevel, meta-analytic review of Hofstede's cultural value dimensions. Journal of Applied Psychology, 95: 405-439.

Templar, K.J. (2010). Personal attributes of expatriate managers, subordinate ethnocentrism, and expatriate success: A host country perspective. International Journal of Human Resource Management, 21, 1754-1768.

Thomas, D. C. \& Lazarova, M. B. (2006). Expatriate adjustment and performance: A critical review. In G. K. Stahl \& I. Bjorkman (Eds.), Handbook of Research in International Human Resource Management: 247-264. Cheltenham: Edward Elgar.

Ting-Toomey, S., \& Kirogi, A. (1998). Facework competence in intercultural conflict: an updated face negotiation theory. International Journal of Intercultural Relations, 22, 187-205.

Ting-Toomey, S. (2005). The matrix of face: An updated- face negotiation theory. In W.B. Gudykunst (Ed.) Theorizing about intercultural communication. Sage: Thousand Oaks, CA: pp.71-92.

Toh, S.M., \& Srinivas, E.S. (2012). Perceptions of task cohesiveness and organizational support increase trust and information sharing between HCNs and expatriate coworkers in Oman. Journal of World Business, 47, 696-705.

Toh, S.M., \& De Nisi, A.S. 2007. HCNs as socializing agents: A social identity approach. Journal of Organizational Behavior, 28, 281-301.

Toh, S.M., \& DeNisi, A.S. (2003). Host country national reactions to expatriate pay policies: A model and implications. Academy of Management Review, 28, 606-621.

Triandis, H.C. (1989). The self and social behavior in differing cultural contexts. Psychological Review, 96, 506-520.

Tsui, A.S., \& Ashford, S.J. (1994). Adaptive self-regulation: A process view of managerial effectiveness. Journal of Management, 20, 93-121.

Tung, R. L. (1987). Expatriate assignments: Enhancing success and minimizing failure. Academy of Management Executive, 1, 117-126.

Tung, R. L. (1981). Selection and training of personnel for overseas assignments. California Management Review, 16, 68-78.

van der Laken, P., van Engen, M., van Veldhoven, M., \& Paauwe, J. (2016). Expatriate support and success: A systematic review of organization-based sources of social support. Journal of Global Mobility, 4(4), 408-431.

Van Dyne, L., Ang, S., \& Nielsen, T.M. (2007). Cultural intelligence. In S. Clegg \& J. Bailey (Eds.), International Encyclopedia of Organization Studies. Thousand Oaks, CA: Sage, 1: 345-350.

Van Kleef, G. A. (2009). How emotions regulate social life: The emotions as social information (EASI) model. Current Directions in Psychological Science, 18, 184-188.

Van Viannen, A.E.M., Pater, I.E.D., Kristof-Brown, A.L., \& Johnson, E. (2004). Fitting in: Surface and deep- level cultural differences and expatriates adjustment. Academy of Management Journal, 47, 697-709. 
Varma, A., Budhwar, P., Katou, A., \& Mathew, J. (2016). Interpersonal affect and host country national support of expatriates: An investigation in China. Journal of Global Mobility, 4(4), 476-495.

Varma, A., Budhwar, P., \& Pichler, S. (2011). Chinese host country nationals' willingness to help expatriates: The role of social categorization. Thunderbird International Business Review, 53(3), 353-364.

Varma, A., Pichler, S., \& Toh, S.M. (2011). A performance theory perspective on expatriate success: The role of self-efficacy and motivation. International Journal of Human Resources Development and Management, 11(1), 38-50.

Varma, A., Toh, S.M., \& Budhwar, P. (2006). A new perspective on the female expatriate experience: The role of host country national categorization. Journal of World Business, 41, 112-120.

Venus, M., Stam, D., \& Van Knippenberg, D. (2013). Leader emotion as a catalyst of effective leader communication of visions, value laden messages, and goals. Organizational Behavior and Human Decision Processes, 122, 53-68.

Wallace, J.C., Butts, M.M., Johnson, P.D., Stevens, F.G., \& Smith, M.B. (In Press). A multi level model of employee innovation: Understanding the effects of regulatory focus, thriving, and employee involvement climate. Journal of Management.

Wallace, J.C., \& Chen, G. (2006). A multi level integration of personality, climate, selfregulation, and performance. Personnel Psychology, 59, 529-557.

Wang, C.-H., \& Varma, A. (2017). Cultural distance and expatriate failure rates: The moderating role of expatriate management practices. International Journal of Human Resource Management.

Webber, L., \& Mayer, K. (2011). Designing effective contracts: Exploring the influence of framing and expectations. Academy of Management Review, 36, 53-75.

Weiss, H.M., \& Cropanzano, R. (1996). Affective events theory: A theoretical discussion of the structure, causes, and consequences of affective experiences at work. Research in Organizational Behavior, 18, 1-74. 
FIGURE 1: Tight-Loose Cultures and Expatriate Adjustment: The Role of Regulatory Fit

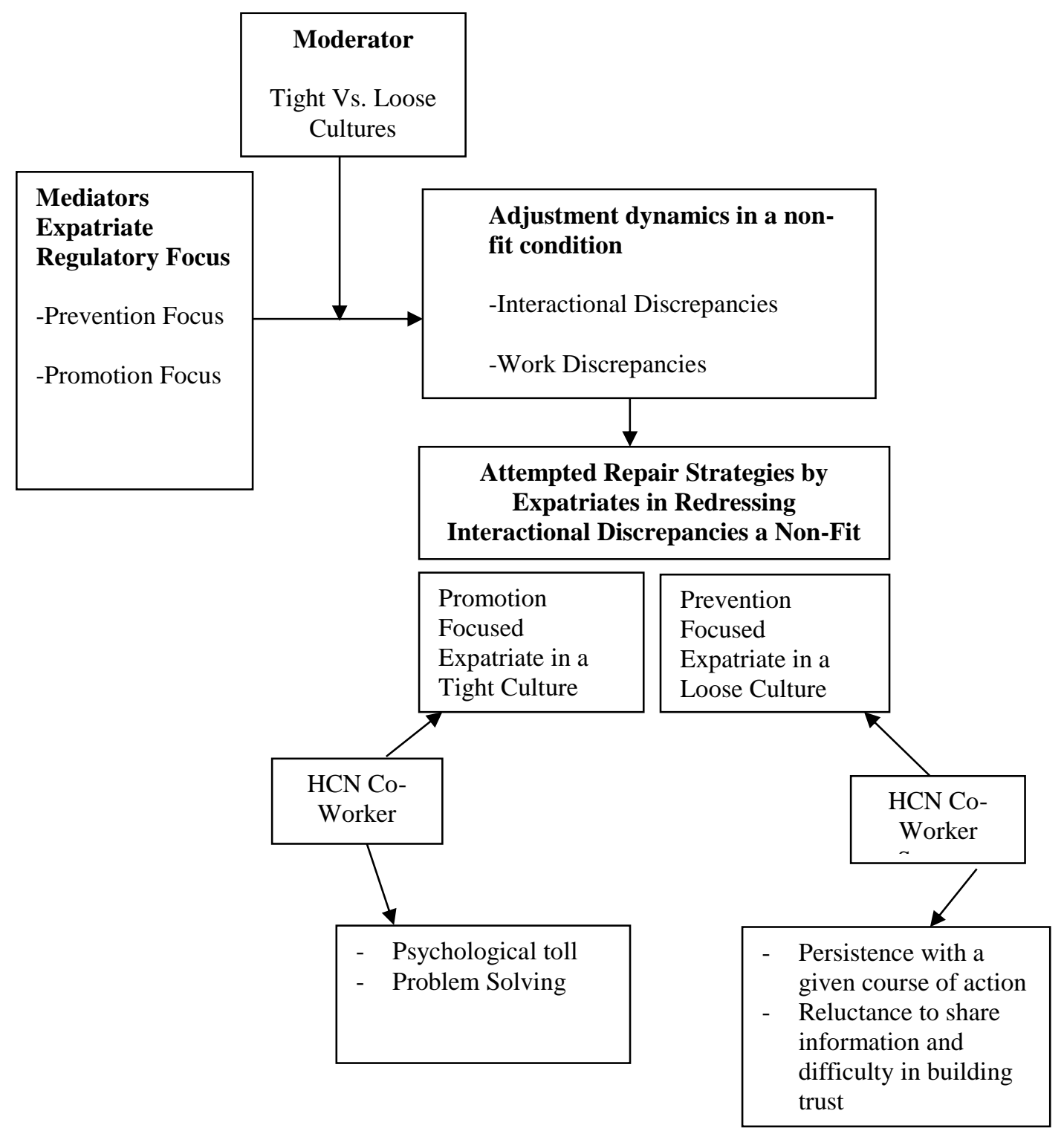

